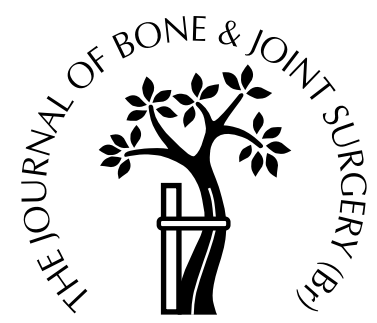

\title{
Primary repair of the cruciate and collateral ligaments after traumatic dislocation of the knee
}

\author{
S. A. Ibrahim \\ From Al Razi Orthopaedic Hospital, Safat, Kuwait
}

T The management of traumatic dislocation of the knee in 40 patients (41 knees) with a mean age of 26.3 years is described. They were treated by primary repair and reconstruction with autologous grafting of the anterior (ACL) and posterior cruciate ligaments (PCL) and repair injuries to the collateral ligament and soft-tissue. The ACL and PCL were reconstructed using the patellar tendon and the gracilis and semitendinosus tendons, respectively. Early mobilisation using a continuous-passive-movement machine and active exercises was started on the second day after operation. At a mean follow-up of 39 months no patient reported 'giving way' and all except one had good range of movement. Of the 41 knees, 21 were rated as excellent, 15 good, four fair and one poor. Early reconstruction of the cruciate ligaments and primary repair of the collateral ligaments followed by an aggressive rehabilitation programme are recommended for these young, active patients.

J Bone Joint Surg [Br] 1999;81-B:987-90. Received 25 September 1998; Accepted after revision 18 January 1999

Traumatic dislocation of the knee is an uncommon injury. The incidence may be higher than recorded because of spontaneous reduction at the time of injury. ${ }^{1}$ It may occur after both high- and low-velocity injuries and is most commonly anterior. ${ }^{2}$ High-velocity injuries are caused by road-traffic accidents whereas low-velocity trauma occurs mainly in sporting activities. There is a significant associated morbidity because of vascular and neurological damage.

The indications for urgent operative treatment are irreducible dislocation, which may be caused by interposition of the pes anserinus, ruptured collateral ligaments, 'buttonholing' of the medial femoral condyle, damage to the popliteal artery or compound dislocation. ${ }^{3-5}$ Examination

S. A. Ibrahim, MD, FRCS Orth, Consultant and Head of the Orthopaedic Unit

Al Razi Orthopaedic Hospital, PO Box 4235, Safat, Kuwait.

(C)1999 British Editorial Society of Bone and Joint Surgery 0301-620X/99/69516\$2.00

VOL. 81-B, No. 6, NOVEMBER 1999 under anaesthesia is essential. Complete dislocation of the knee is impossible without disruption of the posterior cruciate ligament. 6,7

The best method of treatment for ligamentous injuries in dislocation of the knee is not established. One option is initial immobilisation followed by active rehabilitation. 8,9 Advocates of this method claim that it results in a stable, painless knee with a range of flexion of at least $90^{\circ}$. Others have reported good results with early ligamentous repair. ${ }^{10-16}$ However, none has described a postoperative functional grading system, nor did they use a standardised programme for repair and rehabilitation.

There are currently no reports in the orthopaedic literature describing a consistent surgical approach to the management of these patients. The use of allograft has previously been reported ${ }^{17}$ but autologous grafting has not been described for the primary reconstruction of both the anterior (ACL) and posterior cruciate ligaments (PCL).

This study presents the results of reconstruction of the ACL and PCL using autologous grafts of bone-patellar tendon-bone and a double-loop of gracilis and semitendinosus, respectively, in combination with the repair of all the other injured structures. A standardised programme of rehabilitation was implemented in all cases.

\section{Patients and Methods}

Between January 1989 and January 1995, 40 patients with traumatic dislocation of the knee were treated by primary reconstruction of the ACL and PCL with repair of other associated injuries to ligaments and soft tissue. There were 32 men and eight women with a mean age of 26.3 years (18 to 45$)$. One woman had bilateral dislocations, thus giving a total of 41 knees. All patients were treated during the acute phase of injury using the same surgical approach and technique. The injury was caused by a road-traffic accident in 31 patients, sport in two and by accidents at work in seven. There were 12 anterior dislocations, four posterior, three anteromedial, two posterolateral and 20 undetermined. Patients who had sustained a fracture-dislocation or an associated vascular injury were excluded. A careful neurovascular assessment of all patients was made.

Operative technique. We used an anteromedial incision if the medial and cruciate ligaments were injured and both 


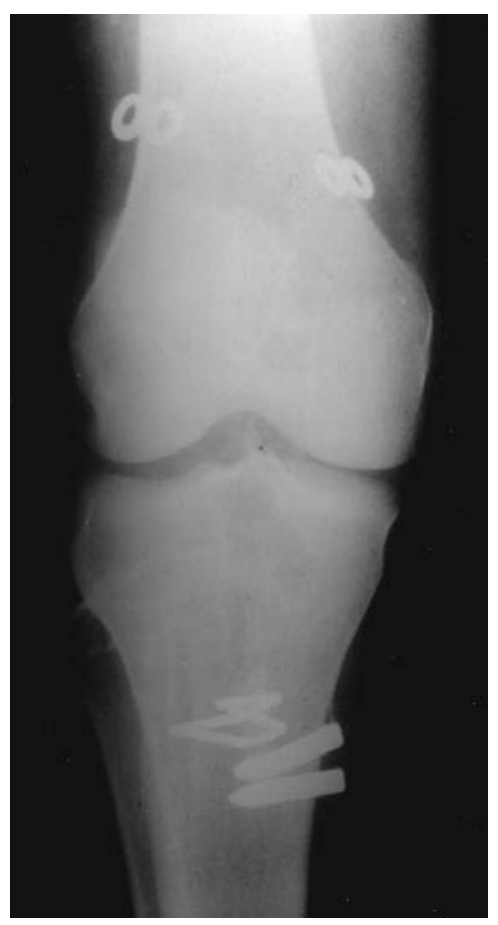

Fig. 1a

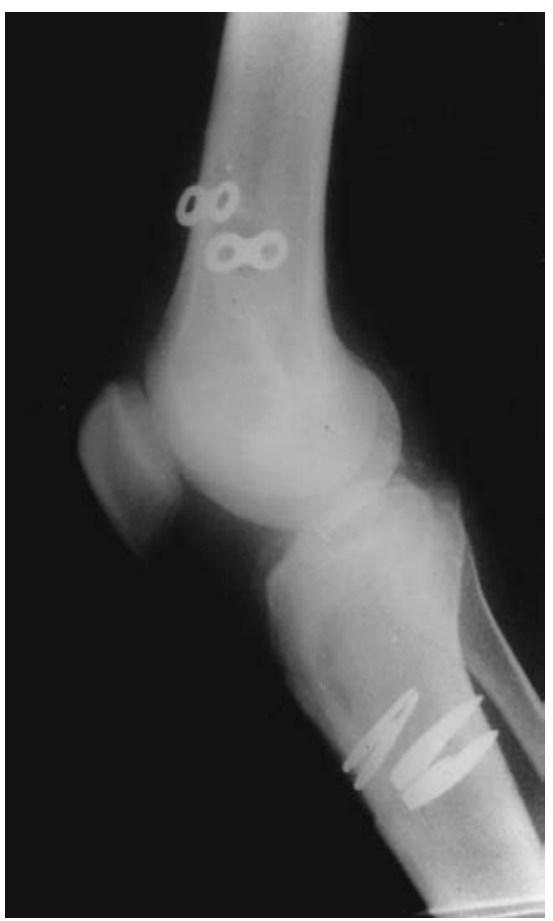

Fig. 1b

Radiographs showing a) anteroposterior and b) lateral views of reconstruction of the ACL and PCL.

anteromedial and anterolateral approaches if the lateral and cruciate ligaments were ruptured. For damage to the lateral structures, sutures were first inserted through the peripheral capsule and then passed through drill holes in the tibia. Peripheral meniscal tears were repaired while a partial meniscectomy was performed for central tears. The arcuate complex was identified and tagged by several sutures which later allowed it to be drawn to its origin on the tibia. The popliteus tendon was retrieved and passed through a bone tunnel. None of these sutures was tied at this stage.

Repair of the medial complex followed the same principles as that for the lateral. Autologous grafts were used for cruciate repair, the middle third of the patellar tendon for the ACL and the tendons of gracilis and semitendinosus for the PCL. Tibial and femoral tunnels were created by drilling over guide-wires at the sites of the isometric points; the tunnel for the ACL graft was drilled first.

The PCL was inserted into the femoral tunnel, then through the tibial tunnel, and the graft was fixed proximally by an endobutton. The ACL graft was then inserted through the femoral and tibial tunnels using endobutton fixation. The knee was placed in full extension and the grafts tightened and fixed by staples or interference screws. All other structures which had been loosely approximated were then tied firmly (Fig. 1). Postoperative mobilisation started on a continuous-passive-motion machine on the second day with an initial range of movement of $0^{\circ}$ to $30^{\circ}$, which was gradually increased. As soon as the range of flexion had reached $90^{\circ}$ active isometric exercises were begun. An intensive programme of physiotherapy was then followed for several months. Electrical therapy of the muscles started when the range of movement had reached $110^{\circ}$.

Assessment. Evaluation of the results included subjective assessment by the patients using a questionnaire, physical examination and radiological evaluation. Functional assessment was graded as excellent, good, fair and poor as proposed by Meyers and Harvey ${ }^{12}$ and Myers, Moore and Harvey. ${ }^{18}$ Patients who were able to return to work and had no symptomatic instability were graded as excellent, those with mild pain or instability which did not preclude return to work as good, those with considerable instability as fair and those who were disabled and unable to return to work because of pain or instability as poor. The Lysholm knee scoring scale was used to assess the functional results. ${ }^{19}$

The IKDC scale was not available in the early period of follow-up and therefore was not used.

\section{Results}

Findings at operation. All patients had complete tears of the ACL and the PCL. Of the ACL tears 34 were midsubstance, four were avulsed from the femur and three from the tibia. Injuries to the PCL included 38 tears at midsubstance, one avulsion from the femur and two from the tibia.

There were 18 ruptures of the medial ligament, 15 at midsubstance, two at the tibial and one at the femoral attachment. The lateral ligament was torn in 13 knees, nine at midsubstance with four avulsions. There were ten lesions of the medial meniscus, three of the lateral meniscus, one 
Table I. Associated injuries in 24 patients with dislocation of the knee

\begin{tabular}{ll}
\hline Type of injury & Number \\
\hline Ipsilateral & 3 \\
Compound fracture of tibia and fibula & 4 \\
Closed fracture of tibia and fibula & 2 \\
Fracture of radius and ulna & 2 \\
Pott's fracture & \\
$\quad$ Contralateral injury & 3 \\
Compound fracture of tibia and fibula & 2 \\
Fracture of the humerus & 3 \\
Fracture of radius and ulna & 4 \\
Fracture of the shaft of the femur & \\
Other injuries & 1 \\
$\quad$ Fracture of the pelvis & \\
\hline
\end{tabular}

avulsion of the belly of the popliteus muscle and one of the tendon of biceps.

Clinical results. Forty patients were observed for a mean of 39 months (29 to 72). The mean interval between injury and surgery was 9.5 days (6 to 15) and the mean hospital stay was 21.3 days (14 to 45 ). Twenty-four patients had other injuries (Table I).

Of the 41 knees, 21 were rated excellent, 15 good, four fair and one poor.

Of the four patients with a fair result one had considerable pain and three mild pain and marked instability. The patient with a poor result had troublesome pain and repeated episodes of giving way. All were able to return to their previous employment at a mean of 11.2 months (3 to 31). The Lachman test was negative in 15, grade 1 in 21 and grade 2 in five knees. The anterior drawer sign was negative in 12, grade 1 in 24 and grade 2 in five knees. The posterior drawer sign was negative in 16, grade 1 in 20 and grade 2 in five knees (Table II). In patients who had injuries of the lateral and medial ligament, it was found that repair of the lateral and posterolateral corner was more difficult than that of the medial ligament and required two incisions. Four of the 13 patients had mild varus instability. Those with rupture of the medial ligament only required one incision and only two out of 18 had valgus instability. One patient with injury to the lateral structures developed heterotopic ossification. The mean postoperative Lysholm knee score $^{19}$ was 79.2 (43 to 97). The mean Tegner activity score was 7.6 before operation which decreased to 4.7 at follow-up (Table III).

Final examination showed a mean flexion of $125^{\circ}$ (115 to 135). Seven had flexion contractures of $5^{\circ}$ or less and one patient had flexion contracture of $15^{\circ}$ while 31 knees had full extension. Seven patients lost the last $10^{\circ}$ to $15^{\circ}$ of flexion.

Radiological assessment. Radiographs showed degenerative changes in the patellofemoral joint in 22 knees at a mean of 31.2 months (23 to 33), in the medial compartment in eight knees and in both the medial and lateral compartments in five. The patient with a flexion contracture of $15^{\circ}$ had heterotopic ossification posterolaterally.
Table II. Clinical results after surgery in 40 patients

\begin{tabular}{llllll}
\hline Grade & $\begin{array}{l}\text { Valgus } \\
\text { instability }\end{array}$ & $\begin{array}{l}\text { Varus } \\
\text { instability }\end{array}$ & $\begin{array}{l}\text { Anterior } \\
\text { drawer }\end{array}$ & $\begin{array}{l}\text { Lachman } \\
\text { test }\end{array}$ & $\begin{array}{l}\text { Posterior } \\
\text { drawer }\end{array}$ \\
\hline Negative & & & 12 & 15 & 16 \\
+1 & 2 & 4 & 24 & 21 & 20 \\
+2 & & & 5 & 5 & 5
\end{tabular}

Table III. Lysholm knee score and Tegner activity score in 41 knees

\begin{tabular}{lllll}
\hline \multirow{2}{*}{$\begin{array}{l}\text { Lysholm } \\
\text { knee score }\end{array}$} & $\begin{array}{l}\text { Number of } \\
\text { knees }\end{array}$ & \multicolumn{2}{l}{ Tegner activity score } & \multirow{2}{*}{\begin{tabular}{l} 
Pumber of \\
\cline { 3 - 4 }
\end{tabular}} \\
\hline 80 to 97 & 15 & Preop & Postop & knees \\
60 to 79 & 17 & 6 to 9 & 4 to 7 & 13 \\
43 to 59 & 9 & 5 to 6 & 5 to 7 & 14 \\
\hline
\end{tabular}

Complications. One patient had a failure of the graft (ACL and PCL) and hence required a revision procedure using the middle third of the patellar tendon and the gracilis and semitendinosus tendons of the contralateral leg.

Two patients developed superficial infection which was treated successfully with antibiotics. Seven complained of pain on walking, at night and in the early morning. Clinical and radiological examination showed that they had degenerative changes. They were treated conservatively with anti-inflammatory drugs and analgesics.

Three patients had peroneal nerve injuries. The woman who had bilateral dislocations sustained damage to the right common peroneal nerve. Of the other two, one had a rupture of the biceps tendon at its insertion into the head of the fibula with a posterolateral dislocation and the other had an anteromedial dislocation. None of the injured nerves was explored at the time of surgery. Neurological recovery was full in two and incomplete in one.

\section{Discussion}

Traumatic dislocation of the knee is a serious injury especially if associated with vascular damage. The incidence of injury to the popliteal artery has been reported as $30 \%$ to $50 \%{ }^{20,21}$ Several authors recommend arteriography in all cases of dislocation of the knee $\mathrm{e}^{21-23}$ since definitive diagnosis and treatment of the arterial injury are essential. Associated nerve injury, usually involving the common peroneal nerve, is seen in $25 \%$ to $40 \%$ of cases. ${ }^{7,24}$ Three of our patients had injury to the peroneal nerve. The type of dislocation was posterolateral in one patient, anteromedial in another and undetermined in the third.

The optimum method of treatment of traumatic dislocation of the knee has not been established. Conservative management usually consists of closed manipulation and immobilisation in a plaster cast. Taylor et al $^{9}$ compared 26 knees managed by closed reduction and immobilisation with 16 treated operatively. They reported good results in 18 of those in the group managed conservatively while only four of the 16 knees undergoing operation had good results. Only three of these knees had primary ligamentous repair. 
Thomsen et $\mathrm{al}^{25}$ reported ten patients of whom four were treated conservatively and six by operation. Of the latter, five had repair of all ruptured ligaments and one of the lateral ligament only. Of the five good, two fair and one poor results, operation had been undertaken in three, one and one, respectively. The poor result was in the patient who had repair of the lateral ligament only. They concluded that operative treatment was indicated for patients with severe instability and that a satisfactory result could be achieved with either operative or non-operative treatment.

Other authors advise reconstruction of the ruptured ACL and PCL after dislocation of the knee. Kennedy ${ }^{11}$ repaired the collateral and cruciate ligaments in six knees and stated that early repair of major ligaments can result in good function. Meyers and Harvey ${ }^{12}$ and Meyers et al ${ }^{18}$ undertook repair of all ruptured ligaments. Of their 16 knees they reported three excellent, ten good, two fair and one poor result. Sisto and Warren ${ }^{16}$ described 20 dislocated knees of which 16 had been treated surgically and four conservatively. Their major complication was loss of movement but they nevertheless recommended surgical treatment in the young active patient. They also advised early manipulation under anaesthesia if flexion was poor. Frassica et $\mathrm{al}^{10}$ reported 17 patients with dislocated knees, 13 of whom were treated by repair or reconstruction of the injured ligaments. Of the 12 who were followed up, five had an excellent result, six were good and one fair. Three patients were treated conservatively and they had a less favourable result. Shelbourne et $\mathrm{al}^{26}$ described ligamentous reconstruction in three patients. The ACL and PCL were repaired in one and three had an isolated PCL autograft. They noted that repair or reconstruction of all injured ligaments gave a stable but stiff knee. It was felt that treating the injury to the PCL alone could provide a stable knee with a good range of movement. Their current treatment is reconstruction of the PCL with an autograft and early aggressive rehabilitation. Shapiro and Freedman ${ }^{17}$ have reported a consistent approach although they use allografts rather than autografts.

Our aim was to restore the normal kinematics of the knee and to prevent or delay the onset of degenerative changes. Stabilisation of the knee allows early mobilisation and weight-bearing.

All our patients returned to their previous employment. The range of movement achieved was adequate for daily activities. Three patients have resumed sporting activities. Arthrofibrosis developed in seven patients despite manipulation under anaesthesia. Shelbourne et $\mathrm{al}^{26}$ found significantly lower rates of arthrofibrosis in patients undergoing reconstruction of the ACL three weeks or more after their injuries.

Following a dislocation of the knee, reconstruction of the ACL and PCL by autologous graft and repair of the other injured structures by the method described together with aggressive rehabilitation, gives functional stability and early return to work.
No benefits in any form have been received or will be received from a commercial party related directly or indirectly to the subject of this article.

\section{References}

1. Siliski JM. Evaluation and treatment of dislocation of the knee. Mediguide Orthop 1992;10:1-7.

2. Green NE, Allen BL. Vascular injuries associated with dislocation of the knee. J Bone Joint Surg [Am] 1977;59-A:236-9.

3. Osmond Clark H. Dislocation of the knee joint with capsular interposition. Proc R Soc Med 1942;35:759.

4. Quinlan AG. Irreducible posterolateral dislocation of the knee with button holing of the medial femoral condyle. J Bone Joint Surg [Am] 1966;48-A:1619-21.

5. Quinlan AG, Sharrard WJW. Posterolateral dislocation of the knee with capsular interposition. J Bone Joint Surg 1958;40-B:660-3.

6. Cooper DE, Speer KP, Wickiewicz TL, Warren RF. Complete knee dislocation without posterior cruciate ligament disruption: a report of four cases and review of the literature. Clin Orthop 1992;284:228-33.

7. Shelbourne KD, Pritchard J, Rettig AC, McCarroll JR, Vanmeter CD. Knee dislocations with intact PCL. Orthop Rev 1992;21:607-8, 610-1.

8. Reckling FW, Peltier LF. Acute knee dislocations and their complications. J Trauma 1969;9:181-91.

9. Taylor AR, Arden GP, Rainey HA. Traumatic dislocation of the knee: a report of forty-three cases with special reference to conservative treatment. J Bone Joint Surg [Br] 1972;54-B:96-102.

10. Frassica FJ, Sim FH, Staeheli JW, Pairolero PC. Dislocation of the knee. Clin Orth 1991;263:200-5.

11. Kennedy JC. Complete dislocation of the knee joint. $J$ Bone Joint Surg [Am] 1963;45-A:889-904.

12. Meyers MH, Harvey P. Traumatic dislocation of the knee joint: a study of eighteen cases. J Bone Joint Surg [Am] 1971;53-A:16-29.

13. Montgomery JB. Dislocation of the knee. Orthop Clin North Am 1987;18:149-56.

14. Roman PD, Hopson CN, Zenni EJ. Traumatic dislocation of the knee: a report of 30 cases and literature review. Orthop Rev 1987; 16:917-24.

15. Shields L, Mital M, Cave EF. Complete dislocation of the knee: experience at the Massachusetts General Hospital. J Trauma 1969; 9:192-215.

16. Sisto DJ, Warren RF. Complete knee dislocation: a follow-up study of operative treatment. Clin Orthop 1985;198:94-101.

17. Shapiro MS, Freedman EL. Allograft reconstruction of the anterior and posterior cruciate ligaments after traumatic knee dislocation. Am J Sports Med 1995;23:580-7.

18. Meyers MH, Moore TM, Harvey PJ. Follow-up notes on articles previously published in the Journal: traumatic dislocation of the knee joint. J Bone Joint Surg [Am] 1975;57-A:430-3.

19. Tegner Y, Lysholm J. Rating systems in the evaluation of knee ligament injuries. Clin Orthop 1985;198:43-9.

20. Jones RE, Smith EC, Bone GE. Vascular and orthopaedic complications of knee dislocation. Surg Gynecol Obstet 1979;149:554-8.

21. Welling RE, Kakkasseril J, Cranley JJ. Complete dislocation of the knee with popliteal vascular injury. J Trauma 1981;21:450-3.

22. Kremchek TE, Welling RE, Kremchek EJ. Traumatic dislocation of the knee. Orthop Rev 1989;18:1051-7.

23. O'Donnell TF Jr, Brewster DC, Darling RC, Veen H, Waltmann AA. Arterial injuries associated with fractures and/or dislocations of the knee. J Trauma 1977;17:775-84.

24. Hill JA, Rana NA. Complications of posterolateral dislocation of the knee: case report and literature review. Clin Orthop 1981;154:212-5.

25. Shelbourne KD, Porter DA, Clingman JA, McCarroll JR, Rettig AC. Low-velocity knee dislocation. Orthop Rev 1991;20:995-1004.

26. Shelbourne KD, Wilckens JH, Mollabashy A, DeCarlo M. Arthrofibrosis in acute anterior cruciate ligament reconstruction: the effect of timing of reconstruction and rehabilitation. Am J Sports Med 1991;19: 332-6. 